group [142 $\pm 44 \mathrm{mmHg}])$. After the onset of mechanical ventilation, $\mathrm{PaO}_{2}$ was $90 \pm 28 \mathrm{mmHg}$ in the $\mathrm{CON}$ group, $118 \pm 48$ $\mathrm{mmHg}$ in the NPPV group ( $\mathrm{p}=0.035$ vs. CON group), and 211 $\pm 59 \mathrm{mmHg}$ in the NPPV+RM group (p $<0.0001$ vs. NPPV group). After ETI, EELV was higher in the NPPV group compared with the CON group ( $<<0.001)$. Compared with NPPV alone, $\mathrm{RM}$ further improved gas exchange and EELV (all $\mathrm{p}<0.05$ ). A significant correlation was found between $\mathrm{Pa} \mathrm{O}_{2}$ obtained 5 min after mechanical ventilation and EELV $(\mathrm{R}=0.41, \mathrm{p}<0.001)$.

Conclusion NPPV improves oxygenation and EELV in children with higher lever intra-abdominal pressure compared with conventional preoxygenation. NPPV combined with early RM is more effective than NPPV alone at improving respiratory function after ETI.

\section{PO-0322 THE EFFECTIVE DOSE OF SODIUM BICARBONATE IN SEVERE ACUTE DEHYDRATION AND METABOLIC ACIDOSIS DUE TO ACUTE DIARRHOEA IN CHILDREN}

M Neamtu, L Dobrota, C Cazan. Pediatric Clinic CCMRP, Pediatric Clinic Hospital "Lucian Blaga" University of Sibiu, Sibiu, Romania

\subsection{6/archdischild-2014-307384.971}

Background Still exist controversies about sodium bicarbonate (SB) effectiveness in metabolic acidosis (MA). The SB dose finally remain at discretion of physician.

Aims Proving SB efficiency in severe acute dehydration (SAD) with MA secondary to acute diarrhoea (AD) in children.

Methods Retrospective study conducted between May-September 2013 , in $0-5$ years old patients hospitalised for AD with SAD and MA. We chose the propitious age group and season for acute gastrointestinal pathology. We considered SAD loss $>10 \%$ of body weight and severe MA pH $<7,2$ and bicarbonate $<15 \mathrm{mmol} / \mathrm{L}$. Not included patients with associated pathology. Were studied 43 medical records; blood gases (BG) assessed at admission, $1 \mathrm{~h}(1 \mathrm{H})$ and $4 \mathrm{~h}(4 \mathrm{H}) .31$ patients received SB (7-2meq $/ \mathrm{kg}$ dose - A Group, 24-1 meq/kg - B Group) and 12 not (C Group).

Results In A Group, at admission, 57,14\% presented $\mathrm{pH}<7,2$, $100 \%$ bicarbonate $<15$; at $1 \mathrm{H}$, all presented normal $\mathrm{pH}$ and bicarbonate $>15$; at $4 \mathrm{H}$, all presented alkalosis. In B Group, at admission, 50\% presented severe $\mathrm{MA}$; at $1 \mathrm{H}, 25 \%$ presented alkalemia, $50 \%$ bicarbonate $<15$; at $4 \mathrm{~h}, 25 \%$ presented alkalosis. In C Group, at admission, 50\% presented bicarbonate $<15$; starting with $1 \mathrm{H}, 91,66 \%$ presented normal BG.

$86,04 \%$ presented respiratory compensation (RC), $\mathrm{pCO}_{2}$ around $20 \mathrm{mmHg}$. Percentage of patients which developed alkalosis was significantly greater in A than B Group (p 0,004); no significance between C and B Group (p 0,57).

Conclusions In choosing the bicarbonate dose in metabolic acidosis, the physician should consider also the RC, especially at $2 \mathrm{meq} / \mathrm{kg}$ dose.

\section{PO-0323 AUDIT ON CARE OF THE FEBRILE CHILD}

${ }^{1} \mathrm{P}$ Donnelly, ${ }^{2} \mathrm{~L}$ McFetridge. ${ }^{1}$ Paediatrics, Antrim Area Hospital, Dunmurry, UK; 2 Paediatrics, Antrim Area Hospital, Antrim, UK

\subsection{6/archdischild-2014-307384.972}

Background and objectives Feverish illness in children is a common reason for hospitalisation. Guidance has been issued by NICE as fever can be a diagnostic challenge. The aim of this audit was to determine if the NICE guideline was being adhered to within the Emergency Department and, if not, where improvement was needed.

Methods This was a retrospective audit reviewing the charts for all children under five years of age attending the Emergency Department within a one month period. These charts were selected using the audit function of the 'Symphony' system. A total of 50 charts were included in the audit. Pyrexia was defined as temperature greater than 37.8

Results $70 \%$ were assessed out of hours.

$62 \%$ had a fever for $<72 \mathrm{~h}$.

$62 \%$ failed to complete a traffic light category for the child.

Only 30\% mentioned hydration status.

Only $6 \%$ assessed for lymphadenopathy.

Only $6 \%$ documented joint examination.

Of those children only reviewed by junior medical staff $44 \%$ sought advice from senior colleagues.

$66 \%$ of children were admitt.ed to the hospital.

$70 \%$ of those discharged from the Emergency department were given a safety net in terms of when to return to hospital.

98\% of children discharged from the Emergency department did not return within the following week.

Conclusion Increased awareness of the NICE guidelines will help improve documentation and ensure that disease specific clinical signs are considered and diagnostic uncertainty is minimised. All cases should be discussed with senior colleagues.

\section{PO-0324 CONDENSED REFERRAL FORMS IMPROVE DATA CAPTURE IN THE NORTHERN IRELAND PAEDIATRIC INTENSIVE CARE UNIT}

${ }^{1}$ P Donnelly, ${ }^{2} \mathrm{~J}$ McCabe, ${ }^{2}$ A Keaney. ${ }^{1}$ Paediatric Intensive Care Unit, Royal Belfast Hospital for Sick Children, Dunmurry, UK; ${ }^{2}$ Paediatric Intensive Care Unit, Royal Belfast Hospital for Sick Children, Belfast, UK

\subsection{6/archdischild-2014-307384.973}

Background and aims Communication is an essential component of high quality medical referrals. The aim was to evaluate the completion of intensive care referral forms and to develop a streamlined document to improve data capture as part of the referral process.

Methods The intensive care referral forms were audited over a three month period to assess degree of completion. A streamlined referral document was subsequently devised using the UK PICS 'Example of essential referral information'. A re-audit was performed to assess for improvement in completion of referral data. Data was collected retrospectively and the new streamlined forms were reviewed as per the proforma set out in the initial audit of January-March 2013. The audit standard was that all sections of the referral form should contain information - 100\% of details for each referral should be recorded.

Results Improvement was noted in a number of sections of the referral form. Completion of patient details improved by $57 \%$. Capture of referral source details, circulatory status and disability status each improved by $7 \%$. Recording of infection status improved by $8 \%$. Recording of transport details improved by $79 \%$. There was no improvement in recording airway status, breathing status or results of any initial investigations. Advice was recorded as being given prior to transfer in $93 \%$ of cases, an improvement of $9 \%$.

Conclusions A concise referral document using UKPICS example has shown an improvement in various areas of data collection. Simplifying the form further may further improve data collection however risks overlooking essential information. 